\title{
Multicriteria Decision Analysis for Renewable Energy Integration Design: For an Institutional Energy System Network
}

\author{
Dharani Rajavelu (D) and Balasubramonian Madasamy \\ Department of Electrical and Electronics Engineering, Alagappa Chettiar Government College of Engineering and Technology, \\ Karaikudi, 630003 Tamilnadu, India \\ Correspondence should be addressed to Dharani Rajavelu; dharani@accetedu.in
}

Received 26 February 2021; Accepted 1 June 2021; Published 15 June 2021

Academic Editor: Philippe Poggi

Copyright ( 2021 Dharani Rajavelu and Balasubramonian Madasamy. This is an open access article distributed under the Creative Commons Attribution License, which permits unrestricted use, distribution, and reproduction in any medium, provided the original work is properly cited.

\begin{abstract}
The hybridization of a renewable energy generator with an existing system in a specific building plays a vital role in solving many important problems of electrical energy systems such as reliability, cost-effective, and ecological option. In this perspective, a modified energy system is proposed in an existing building with integrated renewable energy using multicriteria decision analysis (MCDA). To achieve the sustainable energy solution, the hybrid power source configurations available in the locations are analyzed to ensure reliability using the HOMER software tool. Among these, the best configuration is identified by using the Best Worst Method (BWM) based MCDA approach. The study examined the technical, economic, and environmental perspectives for the achievement of the Sustainable Development Goals (SDGs) such as affordable, reliable, sustainable, and modern energy. The results of the survey in the building show that the best optimal hybrid configuration of the proposed location is the Gird-PV-Wind-based systems for the specific location based on the key techno-economic-environmental criteria of the SDGs.
\end{abstract}

\section{Introduction}

In rapidly growing and most populous countries like India, it is significant to convert the energy found in sunlight, wind, ocean waves, tide, falling water, geothermal heat, or biomass (renewable energy) into electrical energy [1-3]. According to the International Energy Agency (IEA), renewable energy production would surpass coal and become the world's largest source of electricity by the early 2030s. However, in some remote locations, the major disadvantage of a singlesource power station is no more reliable in providing electricity for the continuous period [4]. As a result, over the past few decades, researchers have concentrated on improving the performance of the hybrid renewable energy source (HRES) around the world $[5,6]$. HRES links two or more renewable energy sources for the continuous production of electricity, which must overcome the limits of the single-source energy system $[7,8]$. It has better efficiency, more reliable, and minimum cost of electricity generation in the SDGs (i.e., SDG7). In India, the 2020-Energy Policy Review shows that imple- menting a new framework takes a hybrid approach from point-of-interconnection prediction to a safe, affordable, and sustainable energy system for robust economic growth [9]. The proper selection of HRES generates power for the maximum number of hours in a particular location.

For the lack of focus on optimal design and proper sizing, these energy systems are oversize or have low reliability, which also increases the cost of the system. HOMER is a highly effective optimization software tool that is extensively used for HRES. It gives a wide range of mechanism to optimize, and it is user-friendly, fast in processing [10]. The feasibility studies of hybrid sources of renewable energy, such as wind energy, geothermal energy, and solar energy systems with conventional energy systems in educational buildings are tested and analyzed with different software tools [11]. A new methodology is developed to identify the different configuration problems and maximize the techno-economic benefits of distribution systems for all envisaged cases and scenarios [12]. As well, other studies have identified the most convenient HRES option for the Public Library building, the 


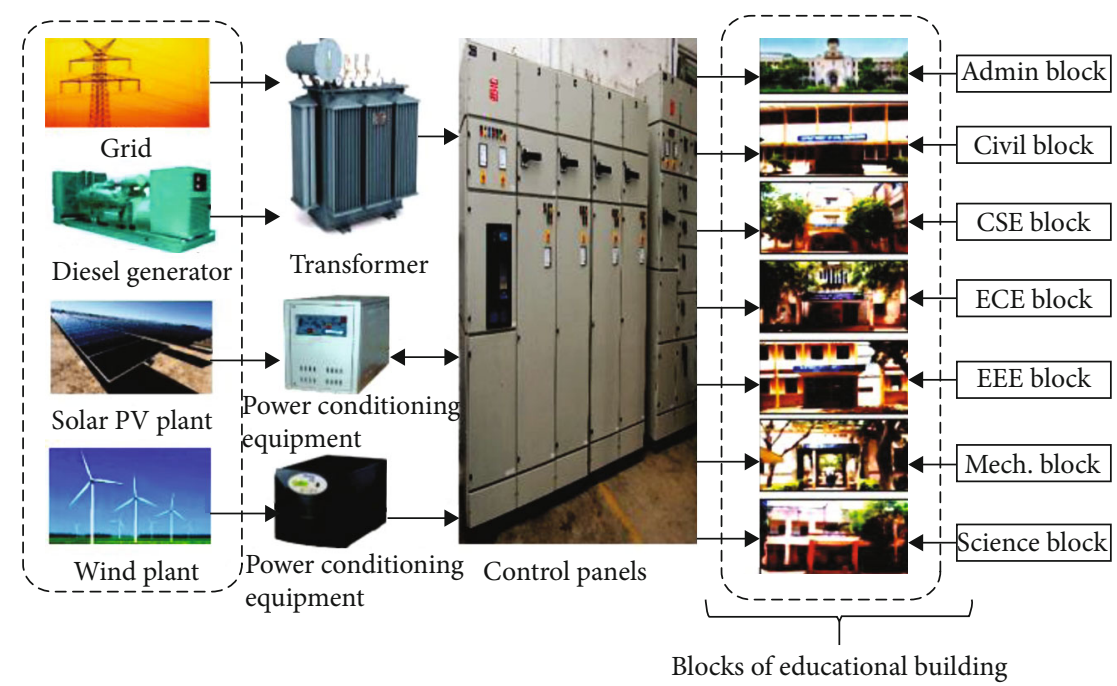

Figure 1: Schematic diagram of the energy distribution network on campus.

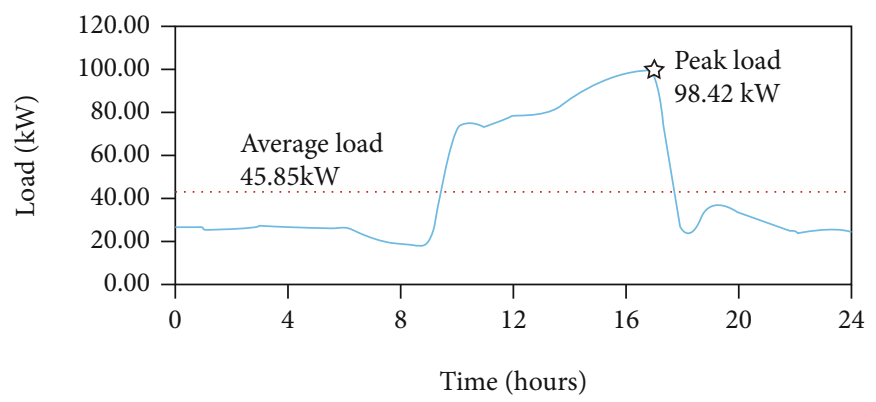

FIGURE 2: Daily load profile of ACGCET campus.

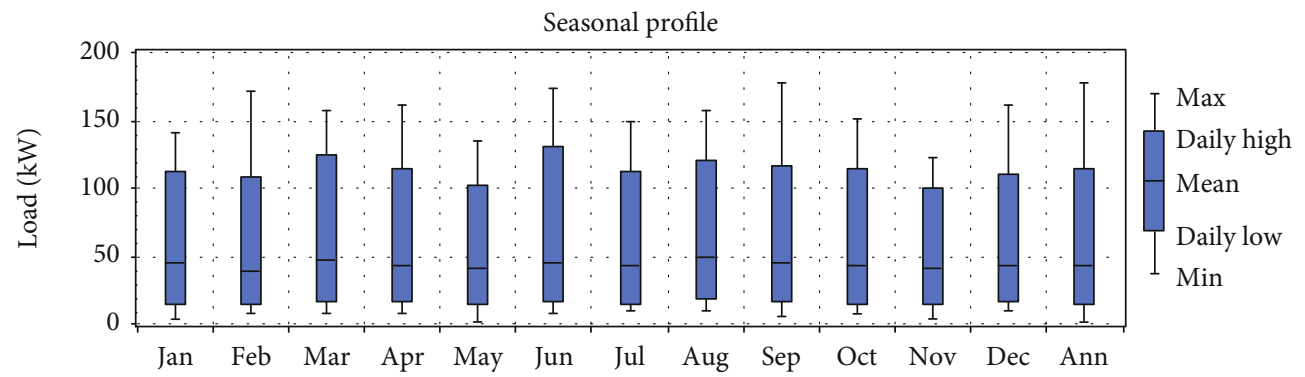

Figure 3: Load profile of the ACGCET campus for each month in a year.

hotel building, and other locations by evaluating the potential for energy sources in the proposed area using HOMER and a similar assessment tool [13-18]. When hybridizing energy sources, over one energy source in the system makes performance evaluation and decision-making complex and requires thorough technical, economic, and environmental analysis. But HOMER fulfills only one objective, such as the identification of the total net cost of energy and cannot be planned for multiobjective issues such as technical, economic, and environmental impacts. A single criterion does not capture and measure the overall performance of the system [19].
It is desirable to analyze different aspects of energy sources, such as technical, financial/monetary, and other external factors while integrating sources, in order to determine the optimum configuration of energy sources. MCDA has become more popular and can provide a methodical and coherent approach to processing multiple performance criteria in both quantitative and qualitative formats [20-24]. This technique was developed to choose the best alternative using different parameter criteria. The purpose of the MCDA is to assist decision makers confronted with such multiple criteria problems in continuous spaces. Multiple-criteria design problems typically require 


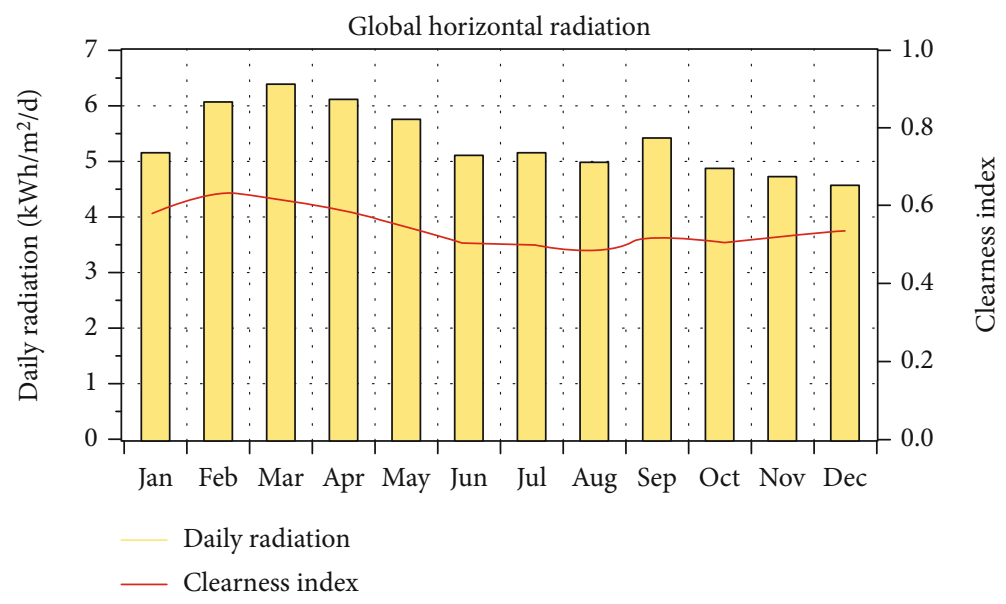

Figure 4: Average solar irradiation level of ACGCET campus.

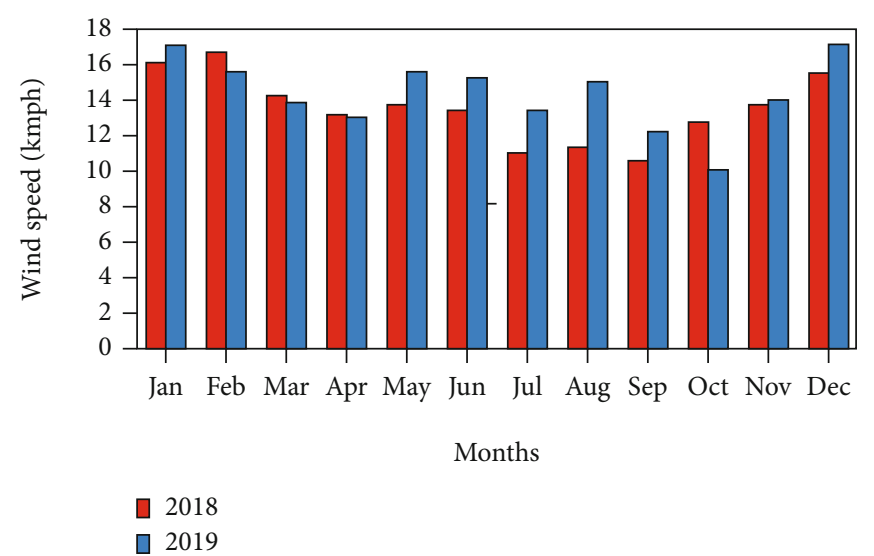

FIGURE 5: Average wind speed of ACGCET campuses.

the solution of a series of mathematical programming models in order to reveal implicitly defined solutions [25]. Pairwise comparisons (through an expert or a team of specialists) are made to demonstrate the relative performance between each of these two criteria (best and worst) and the remaining criteria. A maxi-min problem is predicted and resolved in determining the weights for the various criteria. Weights of alternatives for various criteria are met through an equivalent process in Best-Worst MCDA approach [26, 27].

There is still a lack of specialized work in HRES, in fact by selecting the best hybrid configuration among the energy sources in a particular place by considering various parameters such as economic, technical, and environmental factors. Hence, considering all these essential requirements, the aim of this proposed work is focused on optimum configuration planning and sizing of the different components used in the HRES through Multicriteria Decision Analysis [28] in the study area southern region of India (Karaikudi, Tamilnadu) and to help the decision-makers and identifies the sustainable HRES configuration by including the multicriteria indicators using BWM MCDA method.

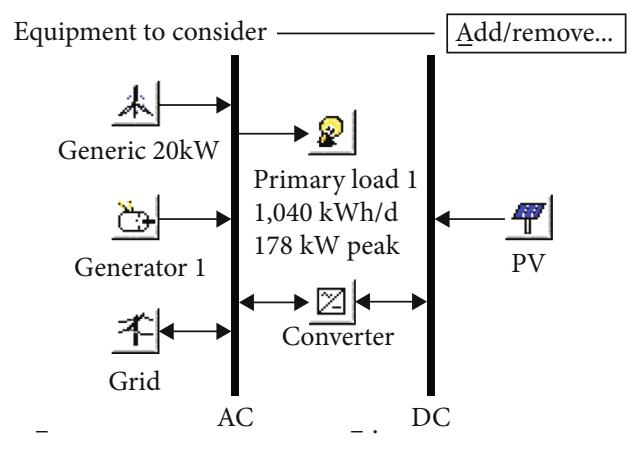

FIGURE 6: Schematic diagram of HOMER simulation model.

\section{Case Study Area: ACGCET Campus}

The study site is at $10.091^{\circ} \mathrm{N}$ and $78.797^{\circ} 91^{\circ} \mathrm{E}$. The campus has a maximum allowable energy demand of $210 \mathrm{KVA}$ from Tamilnadu Generation and Distribution Corporation Limited (TANGEDCO). An electricity distribution network on the ACGCET campus includes an electricity grid line (Electricity Board), solar photovoltaic system, wind and diesel 
TABLE 1: Economic data for simulation.

\begin{tabular}{|c|c|c|c|c|c|}
\hline Existing power source & Capacity (KW) & Capital cost (\$) & Stand-in cost $(\$)$ & O\&M cost $(\$)$ & System life period (years) \\
\hline Diesel generator & 144 & 10214 & 9286 & $0.11^{*}$ & $15000^{*}$ \\
\hline Solar PV array & 20 & 25000 & 22500 & 0 & 25 \\
\hline Wind turbine & 20 & 24300 & 24300 & 250 & 15 \\
\hline Converter & 20 & 280 & 240 & 50 & 20 \\
\hline
\end{tabular}

*per Hours.

generator, distribution panels, automatic power factor correction panels, breaker, cables, and loads. The ACGCET Campus EB invoice includes the cost of energy (CE) per month approximately $\$ 2,857$, the penalty includes the Demand charges per month approximately $\$ 943$ and the compensation for low power factor per month approximately $\$ 100$, and the total cost is $\$ 4,000$ per month (roughly $\$ 48,000 /$ year). In this situation, reducing the energy costs of existing energy sources is required besides reliability and the environment-friendly. Figure 1 shows a complete schematic of the energy distribution system at the study location.

To meet the energy demand at various locations such as the commercial and industrial load campus, different energy sources and its hybrid are involved. In this proposed study location, the energy source configurations, i.e., grid only, grid-diesel generator, grid-wind, grid-photovoltaic, grid-wind-diesel generator, grid-photovoltaic-wind, gridphotovoltaic-diesel generator, and grid-photovoltaic-winddiesel generator are taken for analysis, and best configuration is identified to meet energy demand and manage the distribution network of ACGCET campus with reliability, minimize-cost, and emission free.

Using the load and load duration curve of power distribution network of study location, it is observed that the optimum planning and decision-making analysis play a vital role in the existing electrical network, which leads to identifying the best suitable hybrid power source configuration for ACGCET Campus among renewable or nonrenewable source for more reliable and environmentally friendly energy option. Single Criterion Optimization (COE) is carried out using the HOMER simulation software tool. Second, optimization using multiple criteria, the decision-making problem is carried out using MCDA methods using BWM for three criteria and seven subcriteria like (1) technical: PV capacity factor, renewable fraction; (2) economical: initial cost, cost of energy, return on investment, payback period; (3) environmental: emission.

2.1. Optimization through COE. The proposed HES system is modeled using the HOMER (Hybrid Optimization of Multiple Energy Resources) programming tool to get the best HES configuration via COE. It carries out the simulation of various combinations of the HES considering various sensitive parameters such as technical, economic, and environmental criteria. It is equipped with integrated power converters (DC/DC converter and AC/DC inverters), and distributed and other energy sources critical data are needed to model the HES.
TABLE 2: Configuration parameter.

\begin{tabular}{lcc}
\hline Configuration no. & Name & Notation \\
\hline Configuration I & Grid & G \\
Configuration II & Grid-diesel generator & G-DG \\
Configuration III & Grid-photo-voltaic & G-PV \\
Configuration IV & Grid-wind & G-W \\
Configuration V & Grid-diesel generator-photo & G-DG-PV \\
Configuration VI & Goltaic & Grid-diesel generator-wind \\
Configuration VII & Grid-photovoltaic-wind & G-PV-W \\
Configuration VIII & $\begin{array}{c}\text { Grid-diesel generator-photo } \\
\text { voltaic-wind }\end{array}$ & G-DG-PV-W \\
\hline
\end{tabular}

2.2. Resource Consideration and Load Assessment. The four commonly available resources and their combinations are used in this proposed study: Grid-Solar PV-Wind-Diesel Generator through HOMER tool. Other critical preassessment data are the one-day electrical load profile on the study site. Using these data, sensitive analysis is carried out in the HOMER tool. The average total load and peak demand is noted for 24 hours and is around $45.85 \mathrm{~kW}$ and $98.42 \mathrm{~kW}$, respectively. Figure 2 shows the daily load profile of the ACGCET campus. Geographic and seasonal differences were noted and included in the HES modelling to allow the suggested system could respond load demand with this change. Figure 3 illustrates that the months of March and June are expected to reach the maximum demand, and lowest load demand is reached during February, then in May and November. Therefore, it was advisable to design a HREM for peak loads using campus overall load profile and yearly load profile obtained from the HOMER simulation tool, and approximately, it is taken as $178 \mathrm{KVA}$. The highest maximum load observed in the daily load profile is $98 \mathrm{~kW}$, while the average load was $45 \mathrm{~kW}$ in the specific period. It is also noted that every day the demand for energy is about 1043 $\mathrm{kWh} /$ day.

Meteorological data from the study location were extracted using the National Renewable Energy Laboratory (NREL) web source using campus latitude and longitude $\left(10.091^{\circ} \mathrm{N}\right.$ and $\left.78.797^{\circ} \mathrm{E}\right)$. In this study, the surface of the Earth receives slightly more solar energy almost throughout the year, with relatively long sunny days in summer compared to winter; about it varied from $20.2^{\circ} \mathrm{C}$ to $38.8^{\circ} \mathrm{C}$. The available solar energy database is collected based on weather data, and Figures 4 and 5 show that the mean solar 


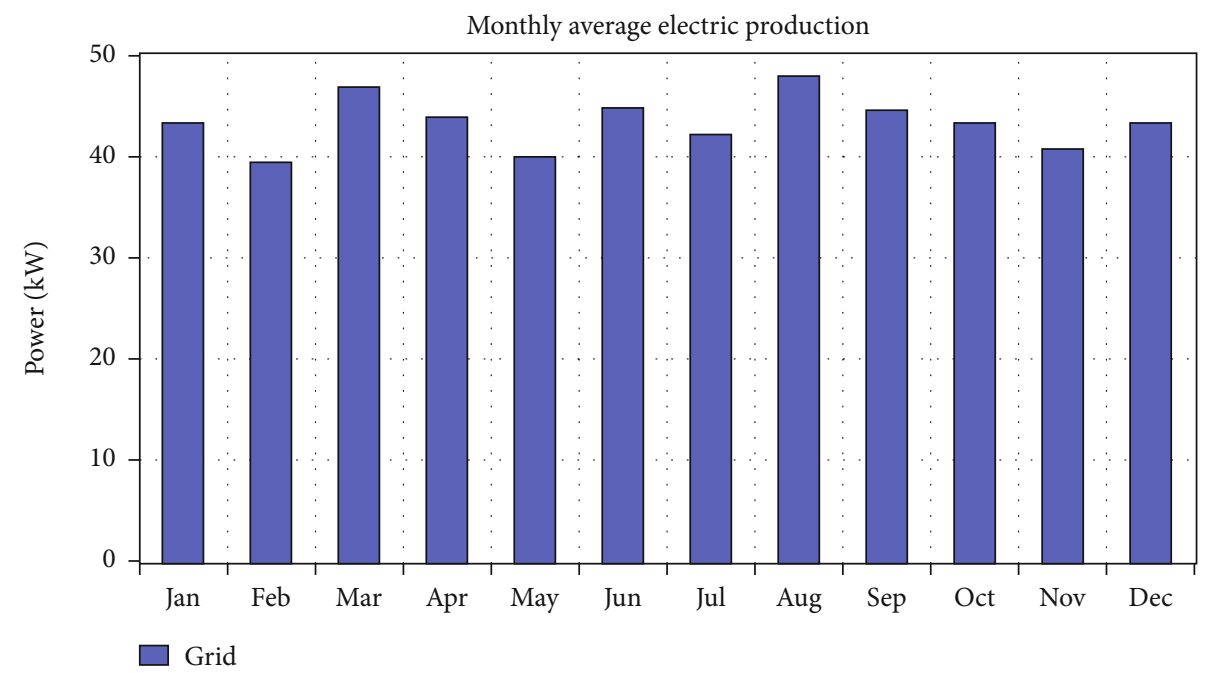

(a) Grid mode

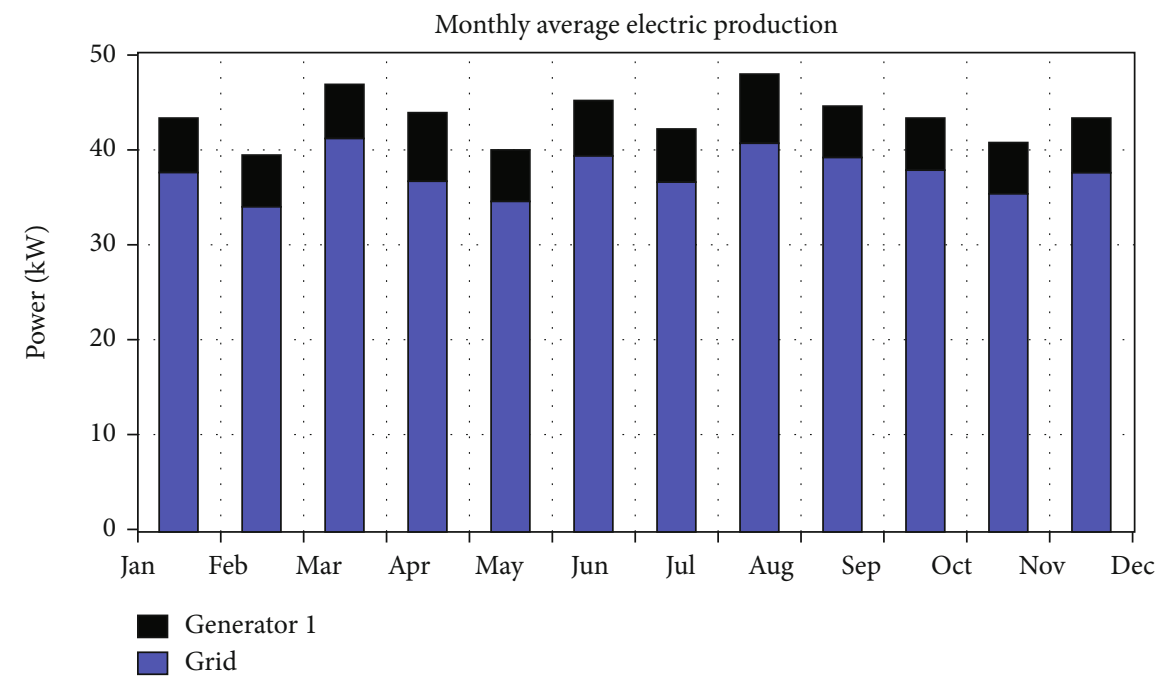

(b) Grid-connected diesel generator mode

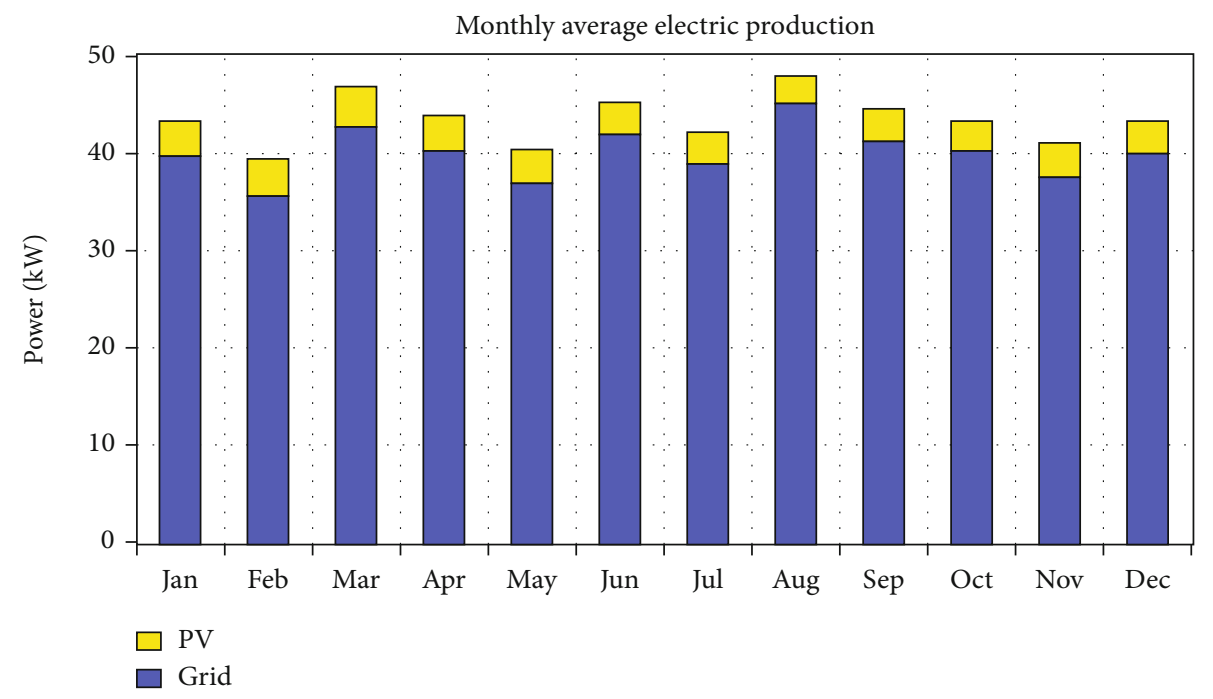

(c) Grid-connected photovoltaic mode

Figure 7: Continued. 


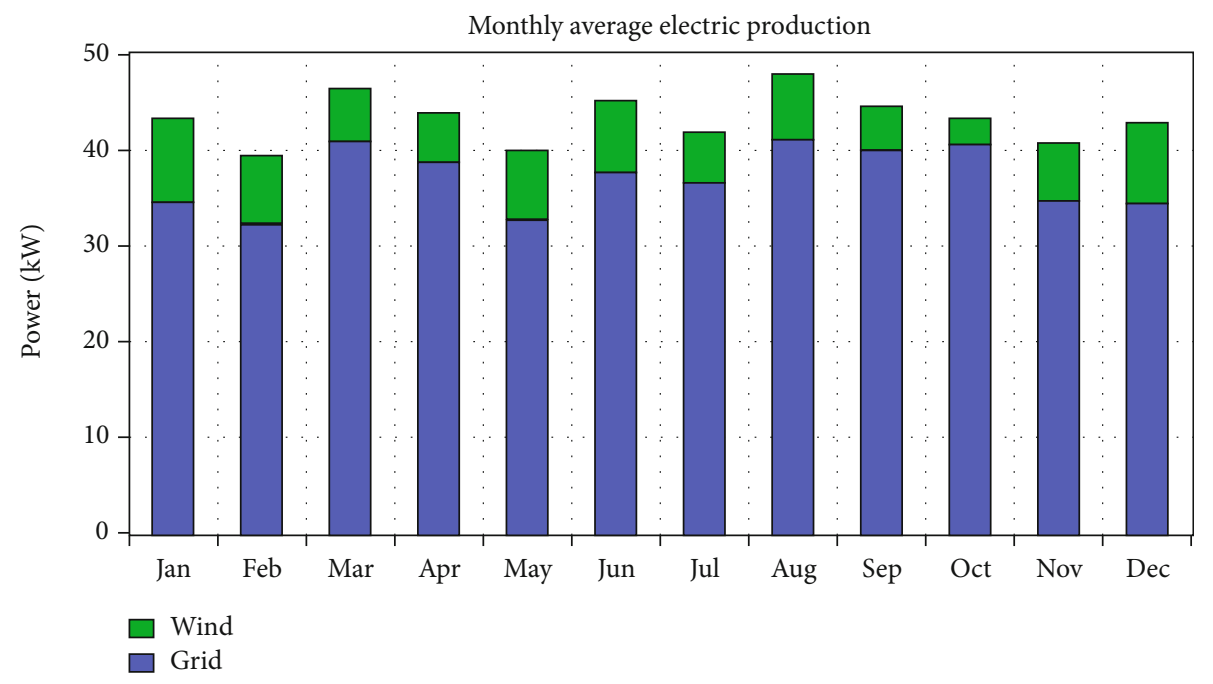

(d) Grid-connected wind mode

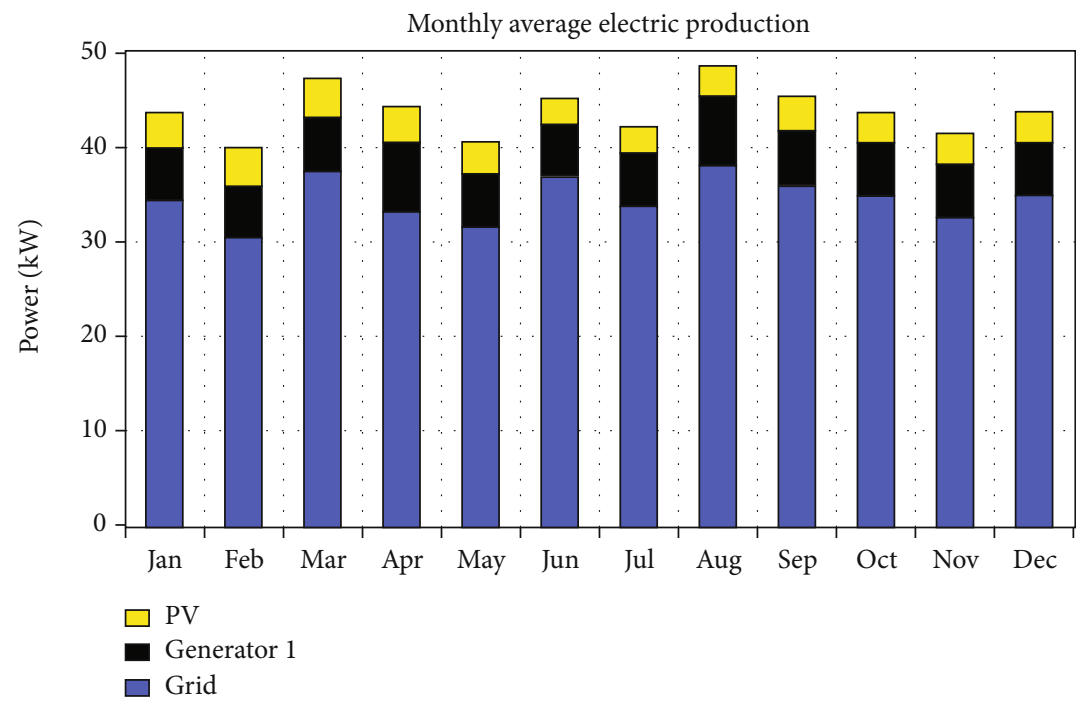

(e) Grid-connected diesel generator and photovoltaic mode

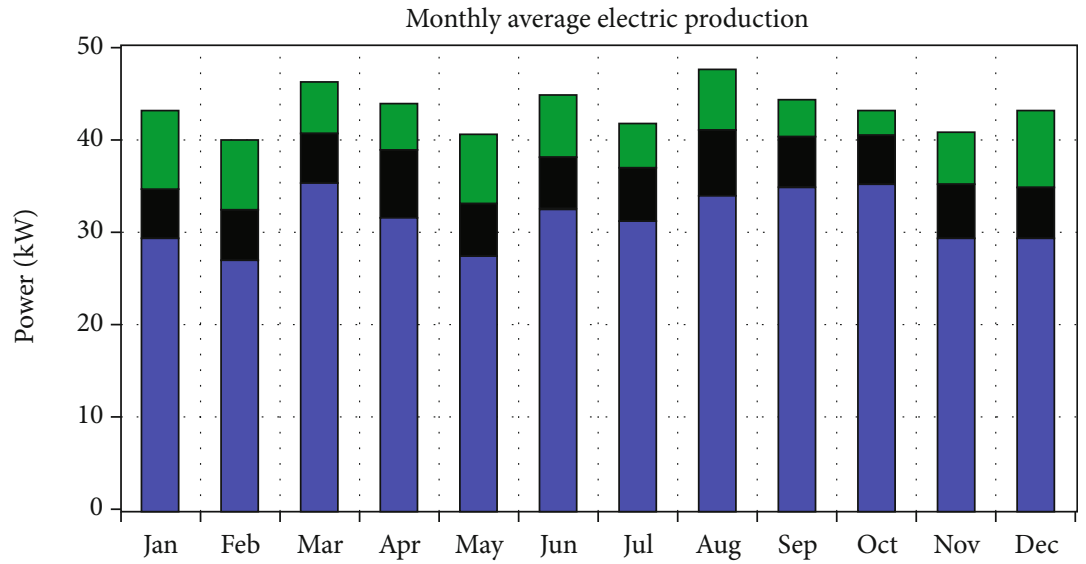

$\square$ Wind

- Generator 1

$\square$ Grid

(f) Grid-connected diesel generator and wind mode

Figure 7: Continued. 


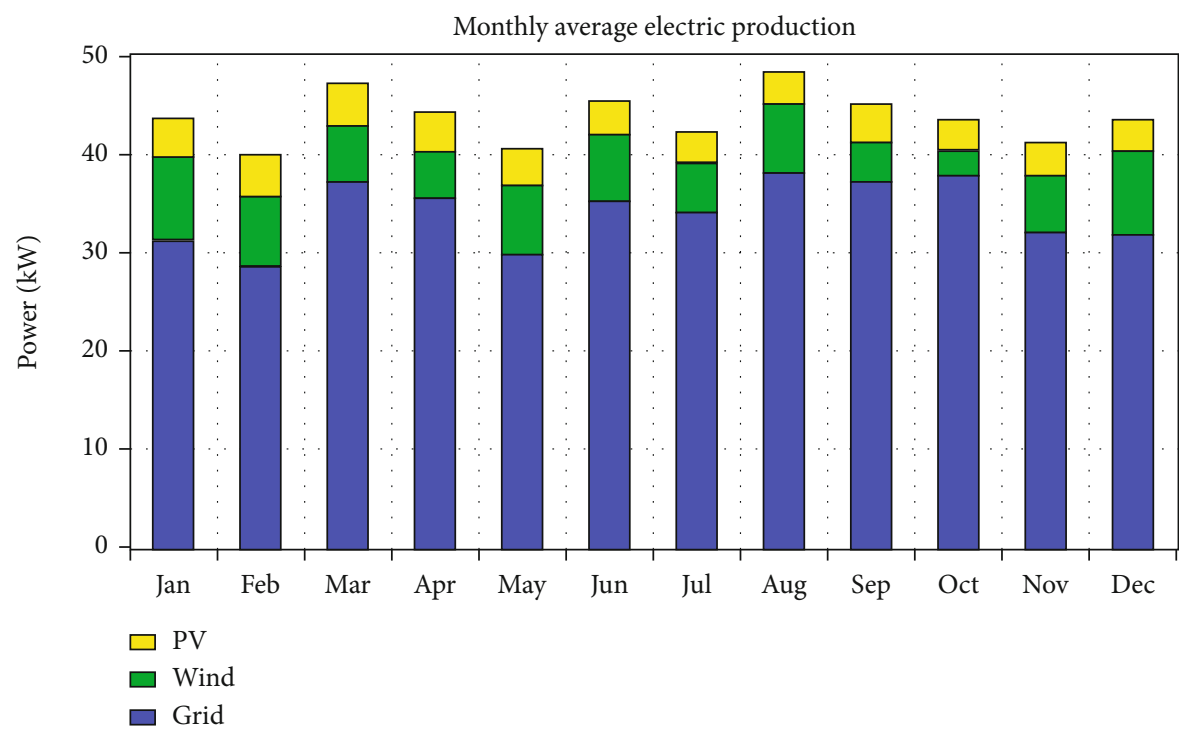

(g) Grid-connected photovoltaic and wind mode

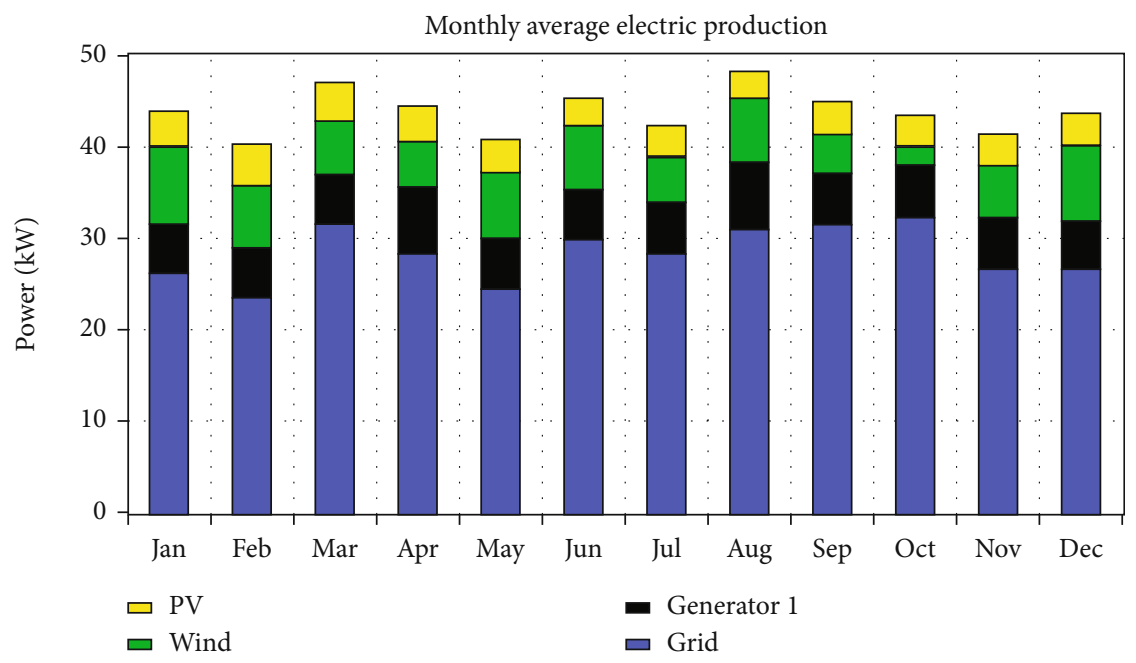

(h) Grid-connected diesel generator and photovoltaic and wind mode

FIGURE 7: Monthly average power production in eight workable HRES configurations.

irradiation level and wind speed of the ACGCET campus per year, respectively. Solar irradiation ranges from 4.45 to 6.42 $\mathrm{kWh} / \mathrm{m}^{2} /$ day. Similarly, the average wind velocity at this location is $13 \mathrm{~km} / \mathrm{h}$.

2.3. Load Following Dispatch Strategy. In existing electricity grid models on campus, various energy sources are considered, including both renewable fuel and fossil fuel generators (diesel generator, grid). Under operational conditions, generator components must be controlled, and this can be accomplished using campus energy allocation strategies. The basic requirement is that satisfy the load power requirements of the test site, although less energy is produced from a grid/renewable/other generator. A Load Following (FL) strategy is involved in this work when optimizing the HREM configuration. It guarantees the load demand is always fulfilled. In this approach, when the power produced by solar photovoltaic generators is lower than the desired load requirements, the LF helps to control the operation of the DG in order to meet the insufficient energy requirements of the ACGCET campus.

\section{The Proposed Energy System Model}

The proposed energy system model works in eight different modes such as grid only mode, grid-diesel generator mode, grid-wind mode, grid-photovoltaic-diesel mode, grid-winddiesel generator mode, grid-photovoltaic-wind mode, gridphotovoltaic-wind mode, grid-photovoltaic-wind mode diesel generator, and grids-photovoltaic-wind-diesel generator mode. The HES model projected into the HOMER simulation tool is illustrated on Figure 6. HOMER simulates every component of the system such as the grid, solar photovoltaic, wind, hydro, diesel generator, battery, AC/DC converters, electrolysis, hydrogen tank, and transformer between values. In this study, the major components are involved: grid, PV 
TABLE 3: HOMER optimization result for different criteria.

\begin{tabular}{lcccccccccc}
\hline Configuration & $\begin{array}{c}\text { Grid } \\
(\mathrm{kW})\end{array}$ & $\begin{array}{c}\text { PV } \\
(\mathrm{kW})\end{array}$ & $\begin{array}{c}\text { Wind } \\
(\mathrm{kW})\end{array}$ & $\begin{array}{c}\text { DG } \\
(\mathrm{kW})\end{array}$ & $\begin{array}{c}\text { Converter } \\
(\mathrm{kW})\end{array}$ & $\begin{array}{c}\text { Total capital } \\
\text { cost }(\$)\end{array}$ & $\begin{array}{c}\text { Total } \\
\text { NPC }(\$)\end{array}$ & $\begin{array}{c}\text { Operating cost } \\
(\$ / \mathrm{yr} .)\end{array}$ & $\begin{array}{c}\text { COE } \\
(\$ / \mathrm{kWh})\end{array}$ & $\begin{array}{c}\text { Renewable } \\
\text { fraction }\end{array}$ \\
\hline G-PV-W & 1,000 & 20 & 20 & 0 & 20 & 49,580 & $4,42,090$ & 30,705 & 0.091 & 0.22 \\
G-W & 1,000 & 0 & 20 & 0 & 0 & 24,300 & $4,52,301$ & 33,481 & 0.093 \\
G-PV & 1,000 & 20 & 0 & 0 & 20 & 25,280 & $4,74,851$ & 35,168 & 0.098 & 0.14 \\
G & 1,000 & 0 & 0 & 0 & 0 & 0 & $4,85,255$ & 37,960 & 0.1 & 0 \\
G-DG-PV-W & 1,000 & 20 & 20 & 144 & 20 & 59,794 & $6,76,241$ & 48,223 & 0.139 & 0.22 \\
G-DG-W & 1,000 & 0 & 20 & 144 & 0 & 34,514 & $6,85,524$ & 50,926 & 0.141 & 0.14 \\
G-DG-PV & 1,000 & 20 & 0 & 144 & 20 & 35,494 & $7,07,979$ & 52,606 & 0.146 & 0.08 \\
G-DG & 1,000 & 0 & 0 & 144 & 0 & 10,214 & $7,17,976$ & 55,366 & 0.148 & 0 \\
\hline
\end{tabular}

TABLE 4: HOMER optimization result for energy production.

\begin{tabular}{|c|c|c|c|c|c|c|c|c|c|}
\hline Configuration & $\begin{array}{c}\mathrm{PV} \\
\text { production } \\
(\mathrm{kWh} / \mathrm{yr} .)\end{array}$ & $\begin{array}{c}\text { Wind } \\
\text { production } \\
(\mathrm{kWh} / \mathrm{yr} .)\end{array}$ & $\begin{array}{c}\text { DG } \\
\text { production } \\
(\mathrm{kWh} / \mathrm{yr} .)\end{array}$ & $\begin{array}{c}\text { Grid } \\
\text { purchases } \\
(\mathrm{kWh} / \mathrm{yr} .)\end{array}$ & $\begin{array}{l}\text { Grid sales } \\
\text { (kWh/yr.) }\end{array}$ & $\begin{array}{l}\text { Grid net } \\
\text { purchases } \\
(\mathrm{kWh} / \mathrm{yr} .)\end{array}$ & $\begin{array}{c}\text { Total electrical } \\
\text { production } \\
(\mathrm{kWh} / \mathrm{yr} .)\end{array}$ & $\begin{array}{l}\text { Diesel } \\
\text { (L/yr.) }\end{array}$ & $\begin{array}{c}\text { DG hours } \\
\text { (hr./yr.) }\end{array}$ \\
\hline G-PV-W & 31,600 & 53,981 & 0 & $2,97,954$ & 776 & $2,97,178$ & $3,83,536$ & 0 & 0 \\
\hline G-W & 0 & 53,981 & 0 & $3,26,093$ & 474 & $3,25,619$ & $3,80,074$ & 0 & 0 \\
\hline G-PV & 31,600 & 0 & 0 & $3,51,159$ & 0 & $3,51,159$ & $3,82,760$ & 0 & 0 \\
\hline G & 0 & 0 & 0 & $3,79,599$ & 0 & $3,79,599$ & $3,79,599$ & 0 & 0 \\
\hline G-DG-PV-W & 31,600 & 53,981 & 49,939 & $2,50,498$ & 3,259 & $2,47,239$ & $3,86,018$ & 25,802 & 1,156 \\
\hline G-DG-W & 0 & 53,981 & 49,939 & $2,77,185$ & 1,505 & $2,75,679$ & $3,81,104$ & 25,802 & 1,156 \\
\hline G-DG-PV & 31,600 & 0 & 49,939 & $3,02,102$ & 882 & $3,01,220$ & $3,83,641$ & 25,802 & 1,156 \\
\hline G-DG & 0 & 0 & 49,939 & $3,29,906$ & 246 & $3,29,660$ & $3,79,845$ & 25,802 & 1,156 \\
\hline
\end{tabular}

array, wind mill, DG with these components, power inverters, and an HES controller. It tests technical and financial options for distributed generation systems. The optimized response shows the list of configurations according to the technical specification of the equipment and other mandatory parameters provided as input and presented in Table 1. The estimated investment costs, operations and maintenance (O\&M), and component capacity replacement costs are also included. The cost was estimated by reference to existing market prices.

In addition, for sensitive analysis, the other sensitivity parameters including wind speed $(\mathrm{m} / \mathrm{s})$, diesel fuel price $(\$ / \mathrm{L})$, the nominal discount rates (\%), and scaled average solar radiation $\left(\mathrm{kWh} / \mathrm{m}^{2} /\right.$ day $)$ rates were used. Meteorological data show that the average solar energy and wind velocity are considered to be in the range of $5-7 \mathrm{kWh} / \mathrm{m}^{2} /$ day and 2$4 \mathrm{~m} / \mathrm{s}$, respectively, in the proposed location, and the nominal discount rates are expected to fluctuate between $5 \%-$ $15 \%$, in India diesel fuel prices of $\$ 0.75$ to $\$ 1.2 / \mathrm{L}$. Finally, HOMER automatically displays the best configuration at the top.

The HOMER calculates the COE for different hybrid configurations using the following equations (1) and (2).

Cost Of Energy $=\frac{\text { total annualized cost }}{\text { total load served }+ \text { total grid sales }}$,
Total annualized cost $=$ annualized capital cost

$$
\begin{aligned}
& + \text { annualized replacement cost } \\
& + \text { annualized o\&m cost } \\
& + \text { annualized fuel cost (if applicable). }
\end{aligned}
$$

The optimization was carried out for the HES configuration modeled according to the data and components. During the optimization process, possibly eight configurations were checked; then, eight HES configurations were compared to a single criterion, like the lowest COE. Different available HES configurations are identified and presented in Table 2. The monthly average power production from the eight workable HES configurations is shown in Figure 7.

\section{Optimization Results}

The optimization results of different criteria and energy production for all configurations using HOMER simulation are presented in Tables 3 and 4 . It can be seen that gridconnected photovoltaic and wind has the lowest NPC, operating cost, and $\mathrm{COE}$ with the highest renewable fraction of 0.22 compared to other configurations.

The analysis of technical parameters, economic and environmental indicators, or emission parameters seems essential to conclude on the best configurations of the HES at the 


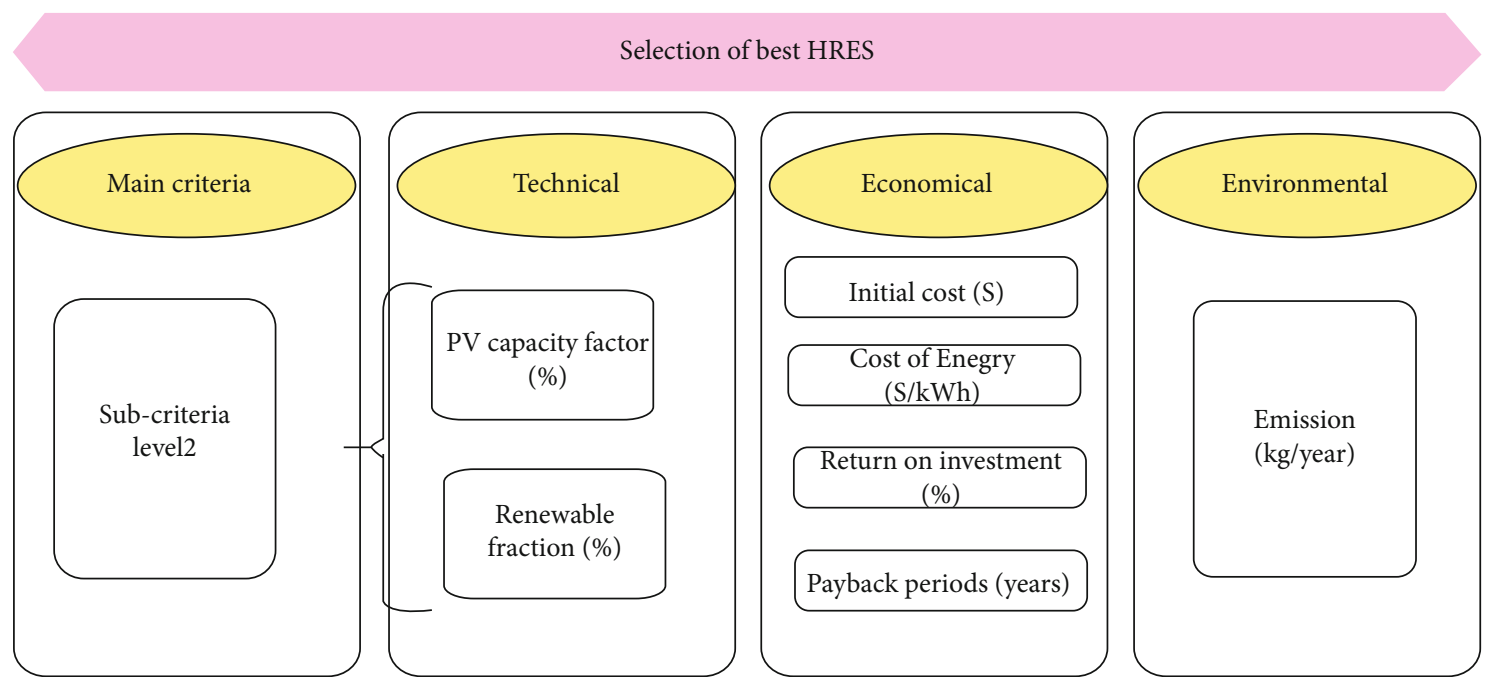

FIGURE 8: Framework of MCDA model for the present case study.

TABLE 5: Scale of other criteria with best criteria.

\begin{tabular}{llccccccc}
\hline Best to others & G & G-DG & G-PV & G-W & G-DG-PV & G-DG-W & G-PV-W & G-DG-PV-W \\
\hline G-PV-W & 7 & 8 & 2 & 3 & 5 & 6 & 1 & 4 \\
\hline
\end{tabular}

study site. The HOMER tool is restricted to a single optimization objective purpose only (COE), but it is necessary to investigate the existing power distribution network of study location with multicriteria parameters such as technical, economic, and environmental factors in addition with a NPC and COE, for which it can be achieved by the MCDA technique.

4.1. Multicriteria Decision Analysis. The MCDA analysis is a very important branch of decision-making theory, which explicitly tests multiple conflicting criteria in decisionmaking. In this research, various sustainable indicators were applied to technologies for integrating renewable energies $[29,30]$. The success of the estimate depends on the effectiveness of the indicators for each criterion that may correspond to a challenge and meet the objective. Figure 8 illustrates the framework work of the MCDA model in this case study.

4.2. Best Worst Method. The Best Worst Method is a new science in Multicriteria Decision-Making theory. MCDA problems have two classes in relation to the problem-solving space: discrete and continuous. Within this framework, varieties of substitutes are tested regarding the number of criteria for selecting the simplest option(s). The objective is to choose the best and the worst (ex: most preferred or most significan$\mathrm{t} /$ least preferred or least significant) criteria are initially determined by the decision-maker $[31,32]$. Table 5 shows the characteristic of BWM, which is that it uses an organized procedure to create pairwise evaluations that lead to consistent outcomes [33-35]. Steps for BWM:

(1) Identify the set of decision criteria

(2) Figure out the best and worst configuration
TABLE 6: Scale of other criteria with worst criteria.

\begin{tabular}{lc}
\hline Others to the worst & G-DG \\
\hline G & 2 \\
G-DG & 1 \\
G-PV & 7 \\
G-W & 6 \\
G-DG-PV & 4 \\
G-DG-W & 3 \\
G-PV-W & 8 \\
G-DG-PV-W & 5 \\
\hline
\end{tabular}

(3) Identify preference for best criteria over all other criteria using a number from 1 to 9 , as indicated in Table 5

(4) Identify preference of all criteria relative to worst using a number from 1 and 9, which is shown in Table 6

(5) Find the optimal weights using equations (3)-(6).

$$
\left|\frac{W_{B}}{W_{J}}-a_{B J}\right| \leq \xi, \quad \text { for all } \quad J
$$

$$
\left|\frac{W_{J}}{W_{W}}-a_{J W}\right| \leq \xi, \quad \text { for all } \quad J
$$




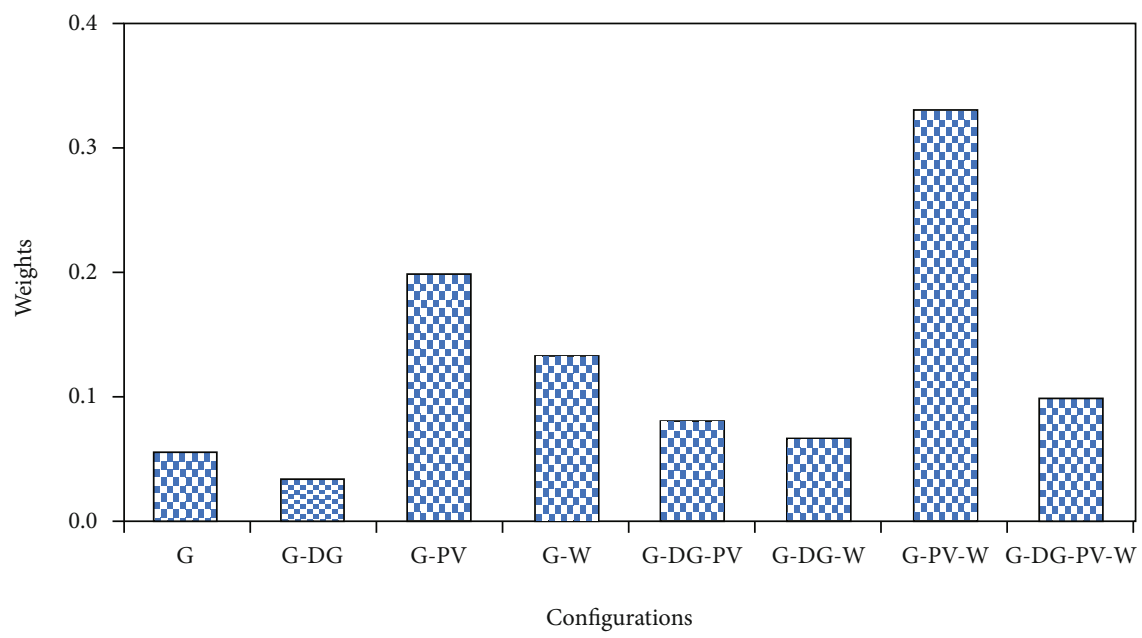

FIGURE 9: Weights of different hybrid configuration using BWM.

TABLE 7: Comparison of emission parameters for different energy system configurations.

\begin{tabular}{|c|c|c|c|c|c|c|}
\hline \multirow[b]{2}{*}{ Configuration } & \multicolumn{6}{|c|}{ Emissions (kg/yr.) } \\
\hline & $\begin{array}{l}\text { Carbon dioxide } \\
\qquad\left(\mathrm{CO}_{2}\right)\end{array}$ & $\begin{array}{l}\text { Carbon monoxide } \\
\text { (CO) }\end{array}$ & $\begin{array}{l}\text { Unburned hydrocarbons } \\
\text { (UHC) }\end{array}$ & $\begin{array}{l}\text { Particulate matter } \\
\text { (PM) }\end{array}$ & $\begin{array}{l}\text { Sulfur dioxide } \\
\left(\mathrm{SO}_{2}\right)\end{array}$ & $\begin{array}{l}\text { Nitrogen oxides } \\
\text { (NO) }\end{array}$ \\
\hline G-PV-W & $1,87,817$ & 0 & 0 & 0 & 814 & 398 \\
\hline G-W & $2,05,791$ & 0 & 0 & 0 & 892 & 436 \\
\hline G-PV & $2,21,933$ & 0 & 0 & 0 & 962 & 471 \\
\hline G & $2,39,907$ & 0 & 0 & 0 & 1,040 & 509 \\
\hline G-DG-PV-W & $2,24,201$ & 168 & 19 & 13 & 814 & 1,828 \\
\hline G-DG-W & $2,42,175$ & 168 & 19 & 13 & 892 & 1,866 \\
\hline G-DG-PV & $2,58,317$ & 168 & 19 & 13 & 962 & 1,900 \\
\hline G-DG & $2,76,291$ & 168 & 19 & 13 & 1,040 & 1,938 \\
\hline
\end{tabular}

$$
\begin{aligned}
\sum_{J} W_{J} & =\xi \\
W_{J} & \geq 0, \text { for all J. }
\end{aligned}
$$

Figure 9 shows the weights (w1, w2, w3, w4, w5, w6, w7, and w8) of various hybrid configurations using BWM, gridconnected photovoltaic with wind system configuration has the highest optimum weight of 0.3321 through BWM MCDA methods.

\section{Results and Discussion}

The result of only one criterion (COE) for all configurations is initially used for the analysis and identification of the best hybrid configuration using HOMER tools. In this section, the multicriteria result is investigated for eight different HREM configurations using MCDA techniques based on PV capacity factor, renewable fraction, and economic indicators. These include initial cost, energy cost, return on investment, recovery periods, and environmental indicators or emission parameters in SDGs 7. The modeled major objective of HRES to satisfy its load demand was served. Based on the weights of the different configuration, the overall load at the study cam- pus was well served by the G-PV-wind HRES configuration. It reveals that the existing electrical system needs to be modernized due to energy inefficiency and high service costs. Finally, as determined by the analyzes, the HRES configuration of G-PV-wind is suggested in SDG 7 based on technical, economic, and environmental criteria and meets average energy demand and peak campus demand.

5.1. Environmental Impact. The environmental impact of all feasible hybrid configurations was compared taking into account six different emission parameters, including $\mathrm{CO}_{2}$, $\mathrm{CO}, \mathrm{UHC}, \mathrm{PM}, \mathrm{SO}_{2}$, and $\mathrm{NO} 2$, and is presented in Table 7. Among all configurations, the system with lower emissions appears to be sustainable $[36,37]$. According to the results of the emissions and environmental analyzers, the G-PV-W configuration is recommended to achieve the sustainable development objective. Compared with other configurations, the $\mathrm{kg} /$ year emission rating is significantly below about $12 \%$.

\section{Conclusion}

This paper presented the multicriteria decision analysis for the optimum design of renewable energy integration of the 
university campus located in the southern state of India. The best hybrid configurations have been identified at a minimal cost of energy demand in a building. In this study for single criteria that is COE consideration, HOMER is applied and for multicriteria parameter such as technical, economic, and environmental aspect BWM-MCDA approach with three main and seven subcriteria such as PV capacity factor, renewable fraction, initial cost, cost of energy, return on investment, payback period, and emission was applied. The results analyzed in the building show that the PV and wind configuration connected to the network (G-PV-wind) has a low COE of $\$ 0.091 / \mathrm{kWh}$ and a high optimal weight of 0.3321 among all configurations considering all criteria parameters. The outcome suggests that G-PV-W is the most appropriate electrical system configuration for this location. In addition, a high renewable fraction was got in the G-PVwind system, and it ensured maximum energy supplied to load and the met peak demand of educational building ACGCET campus by considering the key features of sustainable development goals such as affordable, reliable, and sustainable energy. The results confirmed that in the G-PV-wind configuration $\mathrm{SO}_{2}, \mathrm{NO}$ emissions were significantly reduced and that $\mathrm{CO}_{2}$ emissions were mainly controlled from 2, 76,291 to $1,87,817 \mathrm{~kg}$ per annum, and this represents 28 to 30 percent reductions from other configurations.

\section{Data Availability}

The [input data used in the simulation software] used to support the findings of this study are included within the article.

\section{Conflicts of Interest}

The authors declare that they have no conflict of interest.

\section{References}

[1] Ministry of New and Renewable Energy and Government of India, Annual Reports 2016-2017, 2017, https://mnre.gov.in/ file-manager/annual\%20-report/2016\%E2\%80\%932017/EN/ pdf/1.pdf/.

[2] T. Mai, M. M. Hand, S. F. Baldwin et al., "Renewable electricity futures for the United States," IEEE Transactions on Sustainable Energy, vol. 5, no. 2, pp. 372-378, 2014.

[3] R. M. Elavarasan, G. M. Shafiullah, S. Padmanaban et al., "A comprehensive review on renewable energy development, challenges, and policies of leading Indian states with an international perspective," IEEE Access, vol. 8, pp. 74432-74457, 2020.

[4] J. Zhong, X. Hu, S. Yüksel, H. Dinçer, and G. G. Ubay, “Analyzing the investments strategies for renewable energies based on multi-criteria decision model," IEEE Access, vol. 8, pp. 118818-118840, 2020.

[5] K. Rahbar, C. C. Chai, and R. Zhang, "Energy cooperation optimization in microgrids with renewable energy integration," IEEE Transactions on Smart Grid, vol. 9, no. 2, pp. 1482-1493, 2018.

[6] E. A. al-Ammar, H. U. R. Habib, K. M. Kotb et al., "Residential community load management based on optimal design of standalone HRES with model predictive control," IEEE Access, vol. 8, pp. 12542-12572, 2020.

[7] N. M. Kumar, S. S. Chopra, A. A. Chand, R. M. Elavarasan, and G. M. Shafiullah, "Hybrid renewable energy microgrid for a residential community: a techno-economic and environmental perspective in the context of the SDG7," Sustainability, vol. 12, no. 10, p. 3944, 2020.

[8] G. P. Holdmann, R. W. Wies, J. B. Vandermeer, K. Rahbar, C. C. Chai, and R. Zhang, "Renewable energy integration in Alaska's remote islanded microgrids: economic drivers, technical strategies, technological niche development, and policy implications," Proceedings of the IEEE, vol. 107, no. 9, pp. 1820-1837, 2019.

[9] International Energy Agency (IEA), "India 2020 Energy Policy Review," 2020, https://niti.gov.in/sites/default/files/2020-01/ IEA-India/.

[10] D. Kaur and P. S. Cheema, "Software tools for analyzing the hybrid renewable energy sources: -a review," in 2017 International Conference on Inventive Systems and Control (ICISC), India, 2017.

[11] J. Kim and E. J. Kim, "Simplified method of optimal sizing of a renewable energy hybrid system for schools," Sustainability, vol. 8, no. 11, p. 1134, 2016.

[12] M. R. Elkadeem, M. Abd Elaziz, Z. Ullah, S. Wang, and S. W. Sharshir, "Optimal planning of renewable energy-integrated distribution system considering uncertainties," IEEE Access, vol. 7, pp. 164887-164907, 2019.

[13] B. D. Altay, "Determination of hybrid renewable energy systems for project type public library building," International Journal of Renewable Energy Research Altay and Dursun, vol. 9, no. 1, pp. 24-31, 2019.

[14] J. Dalton, D. A. Lockington, and T. E. J. Baldock, "Feasibility analysis of renewable energy supply options for a gridconnected large hotel," Renewable Energy, vol. 34, no. 4, pp. 955-964, 2009.

[15] M. Z. Malik, A. Ali, G. S. Kaloi, A. M. Soomro, M. H. Baloch, and S. T. Chauhdary, "Integration of renewable energy project: a technical proposal for rural electrification to local communities," IEEE Access, vol. 8, pp. 91448-91467, 2020.

[16] M. T. Al-Nory, "Optimal decision guidance for the electricity supply chain integration with renewable energy: aligning smart cities research with sustainable development goals," IEEE Access, vol. 7, pp. 74996-75006, 2019.

[17] M. Ahmadi, M. E. Lotfy, R. Shigenobu, A. M. Howlader, and T. Senjyu, "Optimal sizing of multiple renewable energy resources and PV inverter reactive power control encompassing environmental, technical, and economic issues," IEEE Systems Journal, vol. 13, no. 3, pp. 3026-3037, 2019.

[18] M. B. Shafik, G. I. Rashed, and H. Chen, "Optimizing energy savings and operation of active distribution networks utilizing hybrid energy resources and soft open points: case study in Sohag, Egypt," IEEE Access, vol. 8, pp. 2870428717, 2020.

[19] T. Wu, D.-L. Xu, and J.-B. Yang, "Multiple criteria performance assessment for decentralized energy systems: a case study," in 2019 5th International Conference on Information Management (ICIM), UK, 2019.

[20] R. I. Mukhamediev, R. Mustakayev, K. Yakunin, S. Kiseleva, and V. Gopejenko, "Multi-Criteria spatial decision making Supportsystem for renewable energy development in Kazakhstan," IEEE Access, vol. 7, no. 7, pp. 122275-122288, 2019. 
[21] A. Kumar, A. R. Singh, Y. Deng, X. He, P. Kumar, and R. C. Bansal, "A novel methodological framework for the design of sustainable rural microgrid for developing nations," IEEE Access, vol. 6, pp. 24925-24951, 2018.

[22] M. Alsayed, M. Cacciato, G. Scarcella, and G. Scelba, "Multicriteria optimal sizing of photovoltaic-wind turbine grid connected systems," IEEE Transactions on Energy Conversion, vol. 28, no. 2, pp. 370-379, 2013.

[23] Department for Communities and Local Government, UK, "Multi-criteria analysis: a manual," https://assets.publishing .service.gov.uk/government/uploads/system/uploads/ attachment_data/file/191506/Mult-crisis_analysis\%20_a_ manual.pdf/.

[24] B. Kumar, A. Sah, R. Singh et al., "A review of multi criteria decision making (MCDM) towards sustainable renewable energy development," Renewable and Sustainable Energy Reviews, vol. 69, pp. 596-609, 2017.

[25] A. Pesola, R. Serkkola, P. Lahdelma, and P. Salminen, "Multicriteria evaluation of alternatives for remote monitoring systems of municipal buildings," Energy and Building, vol. 72, pp. 229-237, 2014.

[26] Z. Wu, S. Zhang, X. Liu, and J. Wu, "Best-worst multi-attribute decision making method based on new possibility degree with probabilistic linguistic information," IEEE Access, vol. 7, pp. 133900-133913, 2019.

[27] J. Rezaei, "Best-worst multi-criteria decision-making method," Omega, vol. 53, pp. 49-57, 2015.

[28] M. A. Sofuoglu, R. A. Arapoglu, and S. Orak, "Multi objve optimization of turning operation using hybrid decision making analysis," Anadolu Üniversitesi Bilim Ve Teknoloji Dergisi AUygulamal Bilimler ve Mühendislik, vol. 18, pp. 595-610, 2017.

[29] J. Vishnupriyan and P. S. Manoharan, "Multi-criteria decision analysis for renewable energy integration: a southern India focus," Renew Energy, vol. 121, pp. 474-488, 2018.

[30] W. Huang, N. Zhang, J. Yang, Y. Wang, and C. Kang, "Optimal configuration planning of multi-energy systems considering distributed renewable energy," IEEE Transactions on Smart Grid, vol. 10, no. 2, pp. 1452-1464, 2019.

[31] X. Mi, "The state-of-the-art survey on integrations and applications of the best worst method in decision making: why, what, what for and what's next?," Omega, vol. 87, pp. 205$225,2019$.

[32] D. J. C. Beemsterboer, E. M. T. Hendrix, and G. D. H. Claassen, "On solving the best- worst method in multicriteria decision-making," IFAC-Papers OnLine, vol. 51, pp. 1660-1665, 2018.

[33] J. Li, J. Wang, and J. Hu, "Multi-criteria decision-making method based on dominance degree and BWM with probabilistic hesitant fuzzy information," International Journal of Machine Learning and Cybernetics, vol. 10, no. 7, pp. 16711685, 2019.

[34] Y. He, H. Guo, M. Jin, and P. Ren, “A linguistic entropy weight method and its application in linguistic multi-attribute group decision making," Nonlinear Dynamics, vol. 84, no. 1 , pp. 399-404, 2016.

[35] H. Gupta and M. K. Barua, "Identifying enablers of technological innovation for Indian MSMEs using best-worst multicriteria decision making method," Technological Forecasting \& Social Change, vol. 107, pp. 69-79, 2016.
[36] V. B. Venkateswaran, D. K. Saini, and M. Sharma, "Environmental constrained optimal hybrid energy storage system planning for an Indian distribution network," IEEE Access, vol. 8, pp. 97793-97808, 2020.

[37] V. B. Venkateswaran, D. K. Saini, and M. Sharma, "Approaches for optimal planning of energy storage units in distribution network and their impacts on system resiliency," CSEE Journal of Power and Energy Systems, vol. 6, no. 4, pp. 816-833, 2020. 